\title{
Una concepción iusadministrativista de los contratos públicos
}

\section{A conception "ius administrativista" of the public}

procurement

JOSÉ LUIS MEILÁN GIL*

Resumen: El artículo analiza las principales características de los contratos administrativos y destaca el enfoque de supraconcepto, común a los contratos privados y públicos. Luego, partiendo de una aproximación desde el Derecho público, se analiza los distintos enfoques doctrinales sobre la naturaleza del contrato administrativo.

Palabras clave: Contrato administrativo - Derecho comunitario - cláusulas exorbitantes - Derecho público - poder público

Abstract: The article analyzes the main characteristics of administrative contracts from the focus of supra concept, common to private and public contracts. Then, starting from the public right, it analyzes the doctrinal approach that differs on the nature of the administrative contract.

Key words: Administrative contract - community law - exorbitant clauses public law authority

\section{ESTADO DE LA CUESTIÓN}

\section{I.1. El contrato administrativo, una figura controvertida}

El contrato ocupa un lugar destacado en la ciencia del Derecho, también en el ámbito del Derecho administrativo. No es necesario insistir en su razonamiento. Por lo que a este se refiere, la categoría del contrato administrativo ha sido objeto de polémica que ha llegado hasta nuestros días ${ }^{1}$. Desconocida o negada en diferentes ordenamientos públicos, con regímenes jurídicos no coincidentes de carácter sustantivo o jurisdiccional, el titular del poder, a lo largo de la historia, ha utilizado la técnica

* Es catedrático de Derecho Administrativo de la Universidad de A Coruña y ex consejero de Estado. Las ideas que se exponen están ampliamente desarrolladas en Meilán, GIL, J. L. La estructura de los contratos públicos. Madrid: lustel, 2008.

1 Como ejemplo, la sostenida en Argentina por los profesores Mairal y Casagne. "De la peligrosidad o inutilidad de una teoría general del contrato administrativo". En El Derecho, t. 179, 1998, Buenos Aires. "Un intento doctrinario infructuoso: El rechazo de la figura del contrato administrativo". En El Derecho, № 9534, 23 de noviembre de 1998, Buenos Aires. También en El contrato administrativo. Segunda edición. Buenos Aires: 2005, pp. 419 y siguientes. 
contractual de un modo directo o por el intermedio de una ficción jurídica (fisco) para atender necesidades que se identifican con el interés de la corona en el Antiguo Régimen, el bien común, el interés de la nación o de los vecinos o los intereses generales en Estados democráticos de Derecho.

El contrato administrativo ha constituido un elemento notorio de diferenciación del régime administratif y de los ordenamientos jurídicos que se han movido en su órbita en Europa y en Latinoamérica con los del rule of law, pero también en Alemania e Italia. El sometimiento de estos contratos, agrupados en un singular a efectos de la exposición, a una jurisdicción especial —el contencioso administrativo con sus variantessería una prueba de esa diferenciación, en ocasiones mostrada como una verdadera causa.

\section{I.2. Influencia de la jurisdicción}

Como la historia revela, no son tanto cuestiones dogmáticas, que se sumarán después, como circunstancias históricas las que explican esas diferencias. En otro sitio he expuesto el origen auténtico de los contratos administrativos como un instrumento público para consolidar la revolución francesa, propiciado por la venta de bienes nacionales. Realizados con la urgencia que presionaba la situación, no era difícil suponer que contenían irregularidades que hubieran sido apreciadas por los tribunales ordinarios compuestos por personas vinculadas al Antiguo Régimen. No se trataba de una naturaleza diferente de la de cualquier otra venta lo que justificó que las controversias jurídicas se ventilasen ante unos tribunales especiales - los corps administratifs nombrados por la administración-, sino que su especialidad vino como consecuencia de que no fuera sometido a los tribunales ordinarios ${ }^{2}$.

Ese oscuro origen, al principio como un estigma, acompañará a la construcción jurisprudencial y teórica de la categoría del contrato administrativo, que se dignificará ligando el contrato administrativo a la idea del service public o a las "obras y servicios públicos" en la tradicional expresión del Derecho español, o más ampliamente el interés público.

La existencia de esa jurisdicción especial para enjuiciar actos y contratos "administrativos" es lo que explica que los contratos de esa naturaleza no hayan sido reconocidos como tales en la órbita del rule of law, por entender que era una improcedente concepción de la división de poderes ${ }^{3}$. Así fue en el origen de la figura y corrobora la configuración del Conseil d'État y la acumulación de poder en él. Aunque su magnífica trayectoria

2 Confróntese el testimonio de Cormenin. Questions de droit administratif. Segunda edición. París: 1823.

3 Es clásica, en ese sentido, la exposición de Dicey: The law of the constitution. 
haya supuesto una gran aportación al control de la administración, es sintomático que haya comenzado con el recurso por "exceso de poder"4.

Quizá haya sido exagerada y errónea la apreciación tradicional inglesa, deudora de la interpretación de Dicey ${ }^{5}$, de entender que el sistema que culmina en el Conseil d'État contiene una serie de derechos especiales, privilegios y prerrogativas "against private citizens", pero es innegable que existen esos privilegios de la administración en función del servicio o interés público.

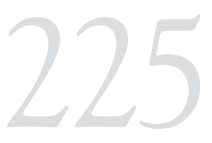

UNA CONCEPCIÓN IUSADMINISTRATI-

VISTA DE LOS

CONTRATOS

PÚBLICOS

A CONCEPTION "IUS

\section{I.3. Derecho comunitario como meeting point de orde- namientos jurídicos}

El no sometimiento a una jurisdicción especial no ha sido obstáculo para que en el seno de la Unión Europea a los government contracts británicos les afecte la directiva europea 2004/117 sobre contratos públicos para el procurement de obras, suministros y servicios que requiera el cumplimiento de los fines que justifica la acción de gobierno. Algo equivalente ha sucedido en Alemania al publicarse, por obligación del Derecho comunitario, las Verdingsordnung que hasta entonces eran instrucciones de servicio de orden interno, en una operación que responde, como en otros asuntos, a un auténtico meeting point de ordenamientos jurídicos de tradiciones diferentes.

Esa concurrencia afecta significativamente, por lo que se expondrá, a la fase de preparación y adjudicación del contrato, con el objetivo de garantizar el principio de igualdad y no discriminación, que es fundamental para la existencia y funcionamiento real del "mercado único" en la Unión Europea. Con esa determinación, la Unión Europea está orientando el análisis de los contratos públicos a poner la atención en esa fase inicial; así deja a la iniciativa de los Estados miembros, y en definitiva de sus ordenamientos nacionales, la regulación de los efectos del contrato, en el que se juegan lo que se ha subrayado como peculiaridades de los contratos administrativos, concretadas en el reconocimiento y ejercicio de prerrogativas de la administración.

\section{I.4. Cláusulas exorbitantes en contratos administrativos y en los sometidos al rule of law}

En los ordenamientos que no reconocen la categoría del contrato administrativo o equivalente, como en los Estados Unidos y el Reino Unido, "los contratos públicos" están sometidos al Derecho privado, lo que no

4 En nuestros días, la figura del comisario del gobierno en el contencioso ha causado perplejidad en la Unión Europea, que ha acogido la de abogado general inspirado en aquella.

5 Confróntese en ese sentido Wade, H. Administrative law. Sexta edición. Oxford University Press, 1989, p. 26. 
es inconveniente a que jueguen cláusulas que no son normales en los contratos entre particulares.

Esto se debe, en unas ocasiones, a que por vía jurisprudencial se limita la prohibición constitucional del impairment que protege la contract clause, apelando al police power, eminent domaine, general welfare, como en Estados Unidos; o en el Reino Unido, que se limita la vinculación contractual apelando a que no se puede impedir la executive action de la corona, el ejercicio del poder, que una autoridad pública pueda realizar las funciones esenciales que justifican su existencia.

En otras ocasiones, se debe a que facultades que equivalen a las prerrogativas se introducen como cláusulas en los contratos que los particulares han de aceptar para que nazca el contrato y que son reproducción de lo que figura en instrucciones internas de servicios ${ }^{6}$ o en contratos tipo. Y, aun en el caso de que no se hayan incluido expresamente, pueden ser operativas si es razonable entender que debieran estarlo?.

En los ordenamientos jurídicos como el español, que reconocen la existencia de prerrogativas de la administración en la ejecución, modificación, extinción de los contratos administrativos, aquellas figuran en normas de carácter general, sin necesidad de tener que repetirse en el clausulado de cada contrato.

\section{I.5. El Derecho civil (privado) como referencia}

No todos los ordenamientos proporcionan un régimen jurídico específico diferente al de los contratos entre particulares, regidos por el Derecho privado, entendido como común. Es lo que sucede en el mundo anglosajón y lo que se ha defendido tradicionalmente en la doctrina alemana e italiana y en la española del siglo XIX y comienzos del XX, que cuenta con "últimos y equivocados epígonos", aunque la presencia de la administración, por sí misma y/o por sus funciones, implique una modulación del contrato que sería civil por naturaleza9.

Tanto para quienes niegan la existencia de un contrato administrativo como para quienes la defienden, el punto de referencia inexorable es el Derecho civil. Como he sostenido con reiteración, la identidad sustancial, la modulación o matización, o el acento puesto en la existencia de cláusulas exorbitantes —obviamente respecto del Derecho civildel planteamiento doctrinal sobre los contratos de la administración ha estado vinculado a una perspectiva civilista.

6 Procurement regulations.

7 G.L. Christian \& Associates v. United States, 1963, 1965.

8 Confróntese Villar Palasí y Villar Ezcurra. Principios de Derecho administrativo. Tomo III. Madrid: Universidad de Madrid, 1983, p. 22.

9 García de Enterría-Fernández, T-R. Curso de Derecho administrativo. Tomo I. Sexta edición. Madrid: Civitas, 1993, pp. 659 y siguientes. 
Desde ella se comprende la tradicional renuencia alemana a aceptar la existencia de un auténtico contrato de la administración con los particulares, dada la desigualdad posicional de ambos y la igualdad exigible de las partes en el contrato civil. El Estado — dirá Otto Mayer — manda siempre unilateralmente y su magisterio durará muchos años ${ }^{10}$.

Esto no ha ocurrido solo con el contrato. La construcción de las categorías propias del Derecho administrativo ha estado dominada por lo que he calificado de mecanismos de imitación y complejo ante el Derecho civil $^{11}$. En la actualidad, sin ofrecer duda alguna de que el Derecho administrativo es Derecho común con capacidad de autointegración, no solo no es imprescindible, sino que construir las categorías del Derecho administrativo desde el Derecho civil puede constituir un obstáculo.

El Derecho civil aparece como un punto de referencia para la calificación de los contratos que celebra la administración con particulares, bien porque se consideren de naturaleza civil, aunque se reconozca la existencia de prerrogativas, bien porque se sometan parcialmente a él los contratos privados de la administración o incluso en aquellas posiciones doctrinales que, al ser partidarias de calificarlos como propiamente administrativos, reconozcan que el Derecho civil es el único derecho común ${ }^{12}$.

La admisión de prerrogativas se acepta desde posiciones que sostienen la naturaleza civil de los contratos denominados "administrativos" y desde las que defienden su naturaleza administrativa.

En el primer caso, esas prerrogativas reconocidas en el Derecho positivo pueden explicarse desde el Derecho civil para contratos en masa y, en todo caso, no "resultan del contrato mismo, sino de la posición jurídica general de la Administración, de su privilegio de autotutela [...] que es en sí mismo extracontracual"13.

En el segundo caso, esas prerrogativas son las que justifican el sometimiento de los contratos administrativos a una jurisdicción especial y proporcionan el fundamento para una naturaleza específica. Así, se explicitan en cláusulas exorbitantes, son siempre válidas en un contrato administrativo a diferencia del civil y, aunque no se incluyan en él, existen siempre ex lege. El derecho objetivo de esta contratación es distinto del de la civil ${ }^{14}$.

10 Confróntese Fleiner. Instituciones de Derecho administrativo. Barcelona: Labor, 1933; Martens, J. y M. Bullinger; Meilán Gil, J. L. La estructura..., pp. 59-62.

11 Confróntese Meilán Gil, J. L. El proceso de la definición del Derecho administrativo. Madrid: ENAP, 1967, pp. 31-35, con citas de Mayer, Wolf, Hauriou, Giannini y Colmeiro.

12 Confróntese Fernández de Velasco, R. Los contratos administrativos. Madrid: 1927, pp. 23 у siguientes.

13 Confróntese García de Enterría, E. "La figura del contrato administrativo". En RAP, № 41, 1963, pp. 112 y siguientes; y Curso... pp. 695 y siguientes.

14 Confróntese Ariño Ortiz. G. Cometarios a la ley de contratos de las administraciones públicas, Tomo I. Granada: Comares, 2002, p. 41.

UNA CONCEPCIÓN IUSADMINISTRATI-

VISTA DE LOS

CONTRATOS

PÚBLICOS

A CONCEPTION "IUS ADMINISTRATIVISTA" OFTHE PUBLIC PROCUREMENT 
Aunque diferentes en las posiciones de partida y en las conclusiones, las prerrogativas se consideran como una cuestión central y su fundamento extra contractum o ex lege permite un punto de aproximación.

Existe también coincidencia en la aceptación de la llamada "zona común" de los contratos celebrados por la administración, relativa a la preparación y adjudicación de aquellos. Reconocida doctrinal y jurisprudencialmente con motivo de su calificación como "actos separables" para resolver un problema presentado en la práctica e impugnar de modo autónomo esos actos en un contrato de la administración regido por el Derecho privado en cuanto a sus efectos ${ }^{15}$, en la actualidad se ha situado en un primer plano por la directiva europea con el fin de asegurar la efectividad del mercado único.

En definitiva, la dialéctica que constituyen el contrato administrativo y el contrato privado está presente en todos los autores, con diferentes matices. El problema central, se dirá, es ver hasta qué punto la construcción del contrato administrativo se independiza de las normas y principios del Derecho civil ${ }^{16}$. En algunos casos esos matices son deudores del concepto doctrinal del Derecho administrativo en el que la administración pública es el elemento clave con referencia a su "giro o tráfico" ${ }^{17}$.

Llámese así o "interés público", "función pública", "servicio público", o de cualquier forma que justifique la existencia del poder en la organización de la convivencia, existe una finalidad pública ${ }^{18}$, con fundamento en el bien común, la felicidad de los súbditos o el servicio a los intereses generales ${ }^{19}$, que explica que existan particularidades en los acuerdos a que el poder llegue con los súbditos o los ciudadanos a lo largo de la historia ${ }^{20}$, en regímenes políticos y sistemas constitucionales diferentes, que se dote, en fin, a los correspondientes contratos de un régimen jurídico especial ${ }^{21}$. En ese sentido, se ha afirmado lapidariamente que el contrato administrativo no es una esencia sino una existencia histórico-jurídica ${ }^{22}$.

15 Confróntese García Trevijano, J. A. "Principios sobre contratos de la administración con especial referencia a la esfera local". Revista de Estudios de la Vida Local, 87, 1956, pp. 301 y siguientes; y otros dos comentarios en la RAP.

16 Confróntese Casagne, J. C. El contrato administrativo. Segunda edición. Buenos Aires: Lexis Nexis, 2005, p. 17.

17 Tesis del profesor García de Enterría, criticada por Villar Palasí. Principios... pp. 29-31.

18 Confróntese Casagne, J.C. El contrato... Ob. cit., pp. 31 y siguientes.

19 Confróntese Meilán Gil, J. L. "Intereses generales e interés público desde la perspectiva de Derecho público español". A\&C. Revista de Direito Administrativo \& Constitucional (en prensa).

20 Confróntese Meilán Gil, J. L. La estructura..., apartado sobre el Antiguo Régimen (pleitos de Colón y descendientes con la corona sobre las capitulaciones de Santa Fe) y el siglo XIX.

21 Confróntese Ariño Ortiz, G. "El enigma del contrato administrativo". RAP, № 172, 2007, pp. 100101.

22 Confróntese Ariño Ortiz, G. Comentarios..., p. 22. 


\section{I.6. El contrato como supraconcepto común a los contratos privados y públicos}

No todo acuerdo es un contrato, sino aquel que vincula a las partes que intervienen en él. Esa vinculación mutua es comúnmente admitida con raíces en el Derecho romano, observada en el Antiguo Régimen ${ }^{23}$ e incluida en los códigos. Un acuerdo de voluntades del que nacen derechos y obligaciones para quienes lo adoptan, con la vinculación mutua ${ }^{24}$ que implica, y que tradicional y alegóricamente ha venido en calificarse de lex inter partes, lex contractus.

La dificultad — anteriormente citada - en Alemania para aceptar el contrato público, en el sentido del administrativo francés, no derivaba de la jurisdicción competente para entender de las controversias que en relación con él se suscitasen, sino de la dificultad de que el Estado se situase en un plano de igualdad con el ciudadano: sería "indigno", se llega a decir (Bullinger). Esa dificultad, con independencia de la concepción allí persistente del Estado, venía favorecida por la identificación del contrato con el Derecho civil, herencia del ius privatum romano que se manifiesta en la referencia a las voluntades de las personas.

Rotas las amarras del Derecho administrativo y sus categorías con el Derecho civil, el planteamiento adecuado y la solución razonable es entender, desde la unidad última del Derecho, que el contrato es un supraconcepto ${ }^{25}$ que abarca contratos que operan en el ámbito privado y contratos que lo hacen en el público.

\section{UNA APROXIMACIÓN DESDE LA PERSPECTIVA DEL DERECHO PÚBLICO}

\section{II.1. Elementos para reformulación de las categorías}

Para un jurista, se ha dicho, el contrato administrativo es un desafío permanente porque requiere una continua reconstrucción jurídica, tanto legal como jurisprudencial ${ }^{26}$. Incluso para quienes sostienen que la sustantividad del contrato administrativo — en singular — es un "falso problema planteado por la doctrina", no deja de reconocerse que "los contratos de la Administración tienen una serie de connotaciones

23 Confróntese Meilán Gil, J. L. La estructura..., pp. 21-22, con citas de Belluga, Vázquez de Menchaca, Dou y Basiguientesols.

24 Como ejemplo, véase Laubadére, Moderne y Devolvé. Traité des contrats administratifs. Segunda edición. París : L.G.D.J., 1983, p. 29.

25 Confróntese Martín Retortillo, S. El Derecho civil en la génesis del Derecho administrativo y sus instituciones. Sevilla: Instituto García Oviedo, 1960, pp. 173 y siguientes, que se refiere al oberbegriff del contrato y razona con la desigualdad de posiciones - existente también en algunos casos de la contratación civil-.

26 Ariño, G. "El enigma...”., p. 101. Confróntese Meilán Gil, J. L. "Para una reconstrucción dogmática de los contratos administrativos". En Anuario de la Facultad de Derecho, № 8, 2005, pp. 505 y siguientes, Universidade da Coruña.

UNA CONCEPCIÓN IUSADMINISTRATIVISTA DE LOS

CONTRATOS

PÚBLICOS

A CONCEPTION "IUS ADMINISTRATIVISTA" OF THE PUBLIC PROCUREMENT 
propias que los diferencian de los contratos privados", aunque de no igual intensidad en todos ellos ${ }^{27}$.

Las concurrencias, en principio sorprendentes, de ordenamientos y opiniones doctrinales diversas sobre varios puntos de la cuestión tratada han de ser tenidos en cuenta en la aproximación a los contratos públicos - en el sentido comunitario- o contratos administrativos - en la tradición franco-belga-española-latino-americana- anunciada al principio a realizar desde la vertiente y la óptica del Derecho administrativo y más concretamente del Derecho administrativo constitucional ${ }^{28}$.

Desde esa perspectiva, ha de partirse de la presencia de la administración como poder público, de su funcionalidad servidora de los intereses generales y de los modos e instrumentos jurídicos utilizados para que ese servicio sea real y efectivo.

\section{II.2. Vinculación del poder público con el interés general}

La Ley 30/2007, del 30 de octubre, de Contratos del Sector Público (en adelante LCSP), como la anterior, en específico referida a contratos de las administraciones públicas ${ }^{29}$, reconoce explícitamente la existencia de contratos administrativos ${ }^{30}$. Es un dato de Derecho positivo. Se vuelve a retomar la distinción entre nominados — de obra, concesión de obra pública, gestión de servicios públicos, suministros, de colaboración entre el sector público y el sector privado, servicios ${ }^{31}-$ y especiales. Su régimen jurídico no ofrece dudas de que es preferentemente de Derecho administrativo, en cuanto a preparación, adjudicación, efectos y extinción, concretado en la LCSP, y de disposiciones de desarrollo en el primer caso y de disposiciones específicas en el segundo.

Coexisten con ellos, como ha sido tradicional, contratos de la administración pública que son privados ${ }^{32}$, con un régimen de Derecho administrativo en cuanto a su preparación y adjudicación ${ }^{33}$, y de Derecho privado en cuanto a sus efectos y extinción.

Los contratos administrativos responden a la configuración constitucional de la administración pública. Se trata de un poder público que sirve con objetividad y eficacia los intereses generales con sometimiento pleno a la ley y al Derecho, como dice el artículo 103 de la

27 Confróntese Villar Palasí, "Principios...”, pp. 18-19.

28 La perspectiva constitucional también es adecuada para el Derecho civil. Confróntese Bacellar Filho, R.F. Direito administrativo e o novo Código Civil. Belo Horizonte: Editora Forum, 2007, pp. 23 y siguientes.

29 Texto refundido aprobado por real decreto legislativo 2/2000 del 16 de junio.

30 Artículo 19.

31 Con excepciones que aquí no interfieren para esa clasificación general.

32 Artículo 20, además de los celebrados por los entes y organismos y entidades del sector público que no reúnan la condición de administración pública.

$33 \mathrm{Se}$ rigen en defecto de normas específicas por la LCSP y sus disposiciones de desarrollo, y se aplican supletoriamente las restantes normas de Derecho administrativo. 
Constitución española. Poder —o función — vicario, no solo sometido a la ley y al Derecho — principio de legalidad y de constitucionalidad-, sino también al titular democrático del poder, en nuestro caso el gobierno, que concreta lo que en un momento determinado signifique ese interés general. Este poder está dotado de cierta capacidad de elección de medios y puede, para ello, dictar normas y producir actos que inciden en las situaciones de los ciudadanos, en sus derechos e intereses.

La administración, por eso, es esencialmente activa. Para ella no es indiferente que sean reales y efectivos los derechos fundamentales reconocidos constitucionalmente, ni la consecución y preservación de lo que se considera como interés general, concepto jurídico indeterminado y variable de acuerdo con los estándares de calidad que se persigan en un determinado lugar y tiempo.

En ese ámbito del interés general —o los intereses generales- opera la actividad contractual de la administración. Esa finalidad es meridiana en los contratos administrativos nominados y razonablemente clara en los especiales "por estar vinculados al giro o tráfico específico de la Administración contratante o para satisfacer de forma inmediata una finalidad pública de la específica competencia de aquella" ${ }^{34}$.

La LCSP contiene una larga enumeración de los entes, organismos y entidades que, dentro del sector público, tienen la consideración de administraciones públicas ${ }^{35}$, las cuales son "poderes adjudicadores" a los efectos del Derecho comunitario.

El concepto de poder adjudicador va ligado también a la idea del interés general. Además de las administraciones públicas, lo son "todos los demás entes, organismos o entidades con personalidad jurídica propia [...] que hayan sido creados para satisfacer necesidades de interés general que no tengan carácter industrial o mercantil" ${ }^{36}$. Se corresponde a la transposición de la directiva europea 2004/18/CE deudora de pronunciamientos jurisprudenciales sobre el alcance del significado de los organismos de Derecho público ${ }^{37}$.

\section{II.3. Predeterminación legal del contrato}

Todos los contratos del sector público en una parte y los administrativos en su totalidad están predeterminados normativamente. El principio de

34 Texto Refundido de la Ley de Contratos de las Administraciones Públicas, artículo 5, 2a.

35 Artículo 3,2.

36 Artículo 3,3,b, de la LCSP.

37 Como ejemplo, véase la decisión prejudicial del 20 de septiembre de 1988, asunto 31/87, "Gebroeders Beentjes BV contra el Estado de los Países Bajos", que tomó como punto de partida para la definición que la noción de Estado debe ser objeto de una interpretación funcional y, por tanto, el organismo en cuestión tiene la condición de poder adjudicador, aunque no esté formalmente integrado en la administración del Estado, por la composición y funciones que lo caracterizan. STJCE del 15 de mayo de 2003, asunto C-214/00, "Reino de España".

UNA CONCEPCIÓN IUSADMINISTRATI-

VISTA DE LOS

CONTRATOS

PÚBLICOS

A CONCEPTION "IUS ADMINISTRATIVISTA" OFTHE PUBLIC PROCUREMENT 
legalidad juega de una manera dominante ${ }^{38}$ frente a la autonomía de la voluntad.

En la autonomía privada, ha dicho el Consejo de Estado, ${ }^{39}$ los valores éticos son un límite; para la administración contratante, un presupuesto de legitimidad de su actuación.

Así se reconoce por la jurisprudencia ${ }^{40}$ :

En derecho civil no cabe duda que el contrato es predominantemente de derecho voluntario, es decir, que las normas que regulan la contratación sólo en aspectos muy concretos (capacidad, materia lícita, causa, formalidades exigidas en ciertos contratos) tienen carácter inderogable para las partes. El artículo 1255 del Código Civil, que dice que "los contratantes pueden establecer los pactos, cláusulas y condiciones que tengan por conveniente, siempre que no sean contrarias a las leyes, a la moral ni al orden público", confirma esta aseveración. También el artículo 1091 del mismo Código: "Las obligaciones que nacen de los contratos tienen fuerza de ley entre las partes contratantes, y deben cumplirse al tenor de los mismos".

En derecho administrativo [...] existe una regulación del contenido sustantivo de los contratos [...].

Así pues, como regla general las normas sobre el contenido de los contratos administrativos son de derecho necesario y no contractual, a diferencia de lo que ocurre en la contratación civil en que la regla es exactamente la contraria.

Esa predeterminación normativa está presente antes de iniciar el procedimiento para su adjudicación. En la documentación preparatoria ha de dejarse constancia de la necesidad e idoneidad del contrato, que han de determinarse con precisión, ya que "los entes, organismos y entidades del sector público no podrán celebrar otros contratos que aquellos que sean necesarios para el cumplimiento y realización de sus fines institucionales" ${ }^{\text {"1. }}$.

Se inicia de este modo el expediente de contratación, en el que se justificará adecuadamente la elección del procedimiento para la selección del contratista y los criterios para la adjudicación del contrato, y al que se incorporarán el pliego de cláusulas administrativas particulares y el de prescripciones técnicas, así como el certificado de la existencia de crédito o documento equivalente y la fiscalización previa de la intervención en su caso ${ }^{42}$.

$38 \mathrm{El}$ artículo 2 declara que los contratos del sector público "están sometidos a la presente ley en la forma y términos previstos en la misma [sic]".

39 Confróntese Memoria, 2004, p. 104.

40 STS del 25 de julio de 1989 (artículo 6114). Ponente: excelentísimo señor Francisco González Navarro.

41 Artículo 22

42 Artículo 93 
Ha de determinarse el plazo de duración del contrato y la previsión de una o varias prórrogas, siempre que las características de aquel permanezcan inalterables ${ }^{43}$.

El contrato tiene un contenido mínimo predeterminado ${ }^{44}$ y un carácter formal, por lo que no puede celebrarse verbalmente ${ }^{45}$. Para celebrar contratos con el sector público, los candidatos han de poseer una determinada solvencia económica y financiera y profesional o técnica, que ha de determinar el órgano contratante, o estar adecuadamente clasificados ${ }^{46}$.

El objeto del contrato deberá ser determinado y su fraccionamiento ha de estar justificado debidamente en el expediente, sin que pueda admitirse para eludir prescripciones de la ley $y^{47}$. El precio ha de ser cierto ${ }^{48}, \mathrm{y}$ debe regularse el valor estimado del contrato ${ }^{49}$, así como la posible revisión ${ }^{50}$. Licitadores, candidatos y adjudicatarios han de prestar garantías ${ }^{51}$.

Existen determinaciones legales concretas según los diferentes contratos. Las administraciones públicas no pueden elegir con absoluta libertad los procedimientos de adjudicación de los contratos que celebren. Ordinariamente se utilizará el abierto o el restringido, y se podrá seguir, en algunos casos, el negociado ${ }^{52}$; asimismo, por lo general, el diálogo competitivo para los contratos de colaboración entre el sector público y el privado ${ }^{53}$.

Los contratos públicos están predeterminados normativamente no solo por la ley, sino por las normas de desarrollo: en primer lugar, por las de carácter reglamentario.

Se produce en esta materia, como sucede con toda normalidad en otros ámbitos del Derecho administrativo, "una integración sucesiva de la norma" o una concreción sucesiva de normas, según la perspectiva desde la que se considere ${ }^{54}$. Existe un auténtico bloque normativo del que, en mi opinión, forman parte los pliegos de cláusulas administrativas generales ${ }^{55}$, que no se identifican con —ni tienen la misma — significación que las condiciones generales de la contratación ${ }^{56}$ en el Derecho privado ${ }^{57}$.

43 Artículo 23. Se suprimió del anteproyecto la fijación del máximo de ellas.

44 Artículo 26 y 120 para contratos de colaboración entre el sector público y el privado.

45 Artículo 28.

46 Artículo 51.

47 Artículo 74

48 Artículo 75. Recogiendo una sugerencia del Consejo de Estado, se mantiene una referencia al mercado mediante la correcta estimación para el efectivo cumplimiento del contrato.

49 Artículo 76.

50 Artículos 77 a 82

51 Artículos 83 a 92

52 Artículo 122.

53 Artículo 164.

54 Confróntese Meilán Gil, J. L. La distinción entre norma y acto administrativo. Madrid: ENAP, 1967, pp. 45 y siguientes.

55 Confróntese Meilán Gil, J. L. La estructura..., pp. 171 y siguientes.

56 En ese sentido, véase el dictamen del Consejo de Estado de 16/11/1995.

57 La ley $7 / 1998$ del 13 de abril, que traspuso la directiva 93/13/CEE del Consejo del 5 de abril, no es de aplicación a los contratos administrativos, modificada puntualmente por la ley de enjuiciamiento civil.

UNA CONCEPCIÓN IUSADMINISTRATIVISTA DE LOS CONTRATOS PÚBLICOS

A CONCEPTION "IUS ADMINISTRATIVISTA" OFTHE PUBLIC PROCUREMENT 
La selección del adjudicatario del contrato deberá recaer en la proposición económicamente más ventajosa, y atenderá a criterios directamente vinculados al objeto del contrato, entre los que entran, como consecuencia de la evolución del Derecho comunitario, características medioambientales o sociales. Cuando solo se utilice un criterio, este ha de ser necesariamente el del precio más bajo ${ }^{58}$.

Por lo que se refiere al cumplimiento de los contratos administrativos, deben respetarse sus cláusulas "sin perjuicio de las prerrogativas establecidas por la legislación a favor de las Administraciones Públicas" ${ }^{29}$, a saber de interpretación, resolución de dudas, modificaciones "por razones de interés público", resolución y determinación de sus efectos ${ }^{60}$. Estas son expresas determinaciones ex lege de los contratos ${ }^{61}$.

\section{II.4. El contrato como ejecución de la norma}

Para el cumplimiento de su función constitucional, la administración ha de actuar. Los fines del Estado no pueden alcanzarse con el puro establecimiento de leyes que contienen, sin embargo, los objetivos a conseguir. La administración pública puede desarrollar la ley mediante el ejercicio de una potestad normativa. Esto no siempre es suficiente: es precisa una aplicación a situaciones concretas de las que se derivan derechos y obligaciones. Esa actuación puede tener un carácter unilateral, típico del acto administrativo; o el bilateral, propio del contrato.

La historia y los diferentes ordenamientos y la práctica política revelan con claridad el uso instrumental de una u otra categoría jurídica ${ }^{62}$. De un modo tendencial podría afirmarse una preferencia por la imposición unilateral. La administración, en cuanto puede, huye del contrato; pretende evitar la pesada carga que — en frase de Forsthoff- supone la doble vinculación del acto administrativo. Este se encuentra en el nacimiento y desarrollo de los contratos administrativos (actos de poder y de gestión) y permanece en su estructura (actos de información, anuncio de licitación, acto de admisión, adjudicación).

Expresado de un modo propio de la dogmática jurídica, en el Derecho administrativo nacen derechos y obligaciones directamente de la norma o de su ejecución. Desde ese planteamiento no debería resultar sorprendente sostener que el contrato en el Derecho administrativo opera en

Confróntese Martínez de Aguirre Aldaz. Curso de Derecho civil. Derecho de obligaciones. Madrid: Colex, 2000, pp. 389 y siguientes.

58 Artículo 134. Es una constante de la regulación de los contratos administrativos, como se expuso en anterior apartado.

59 Artículo 193.

60 Artículo 194.

61 Se prescinde aquí del examen del completo bloque normativo que responde al proceso de desarrollo de la LCSP. Confróntese Meilán Gil, J. L. La estructura..., pp. 167 y siguientes.

62 Confróntese Meilán Gil, J. L. La estructura..., pp. 19-52. 
una cierta relación dialéctica con el acto administrativo. Dicho de otro modo, la actividad contractual de la administración no se entiende cabalmente sin referencia al acto administrativo.

En último término, el contrato de la administración no se explica por su referencia al principio de la voluntad, como el civil, sino por la necesidad de la administración de llevar a cabo la ejecución de una norma ${ }^{63}$ cuyo objetivo es realizarse.

Esta es una aproximación deliberadamente formal, aunque resulta obvio que la "ejecución de la norma" hay que entenderla en el contexto material de "realización" ligado este al complejo de ideas que subyace en expresiones como "obras y servicios", "prestaciones administrativas", "utilidad pública", "interés social", "procura existencial", "interés público", "derechos fundamentales" y, en definitiva, con las formulaciones y principios constitucionales del Estado social y democrático de Derecho, que rebasan un mero positivismo jurídico ${ }^{64}$.

\section{I.5. La vinculación contractual}

La construcción more privato como acuerdo de voluntades dificulta la comprensión del papel de la administración en relación con la declaración de voluntad del particular en los contratos públicos. La administración opera a través de actos que son resultado del ejercicio de una potestad habilitada por la norma. No ofrece dudas que el in fieri del contrato se encuentra absolutamente dominado por actos administrativos, con lo que eso supone de sometimiento al principio de legalidad y demás principios, entre ellos el de "buena administración". En ese sentido, hablar de autonomía de la voluntad de la administración es un antropomorfismo que a menudo se utiliza también para la definición del acto administrativo.

La existencia de actos en el procedimiento que sigue la administración para participar en el acuerdo que implica el contrato es una clara diferencia de los contratos administrativos y de los suscritos entre particulares ${ }^{65}$. La importancia de ese procedimiento explica que se haya puesto especial énfasis en la "adjudicación" del contrato y que sea calificada de diferente manera.

63 Martens, J. "Normenvollzug durch verwaltungsakt und verwaltungsvertrag". Archiv des Offentlichen Recht, № 89, 1964; y Villar Palasí y Villar Ezcurra, óp. cit., p. 2.

64 Confróntese Meilán Gil, J. L. La estructura..., pp. 19 y siguientes.

65 Esa misma diferencia subsiste entre estos y los privados de la administración. Es en lo que pone énfasis una norma clave en la historia de los contratos administrativos: el real decreto del 27 de febrero de 1852, debido a Bravo Murillo, el principio de publicidad para asegurar la igualdad entre los concurrentes. Para México, confróntese Fernández Ruíz, J. "Los contratos administrativos y negocios jurídicos afines del ámbito federal mexicano". Casagne y Rivero Ysern (directores). La contratación pública. Buenos Aires: Hanmurabí, 2006, pp. 164-194.

\section{IUSADMINISTRATI- VISTA DE LOS CONTRATOS PÚBLICOS}

CONCEPCIÓN

A CONCEPTION "IUS ADMINISTRATIVISTA" OF THE PUBLIC PROCUREMENT 


\section{II.5.1. Algunas posiciones doctrinales}

En la doctrina española, tempranamente se sostuvo que "la adjudicación perfecciona el vínculo contractual, porque con ello la Administración acepta la oferta del licitador seleccionado para contratista". En otras palabras, "la adjudicación, como acto administrativo, produce unilateralmente consecuencias jurídicas y, además, por ser aceptación de una oferta, origina un contrato" ${ }^{66}$.

La relevancia atribuida al acto ha ido subrayándose hasta lo que podría denominarse radicalización en un proceso lógico respetable, aunque no se comparta.

El redactor principal de la ley de contratos del Estado de 1965 sustentó la teoría del contrato del Estado como "acto de la Administración" ${ }^{67}$. La obligación contractual del Estado "no podrá derivar del mero concurso de la oferta privada y la aceptación de este órgano"68. La fuerza vinculante de esa aceptación no surgiría del concurso de voluntades de administración y particular, "sino de la potencialidad jurídica que emana del acto administrativo, fruto de un procedimiento de contratación reglado, en el cual la adhesión de la voluntad privada es una pieza más de las varias actuaciones y resoluciones que componen el sistema"69.

Se da un paso en la dirección que estimo acertada para el entendimiento de los contratos administrativos, ya que, al existir un poder — públicoen estos, resulta menos adecuado sostener que la administración acepta la oferta del particular — contratista - que la inversa.

La importancia de la adjudicación en el iter del contrato se manifiesta legalmente, al decirse que los contratos de las administraciones públicas se perfeccionan mediante la adjudicación definitiva ${ }^{70}$. Esta dicción ha llevado a sostener en sede doctrinal ${ }^{71}$ que esos contratos nacen de la voluntad unilateral de la administración, en ejercicio de su potestad pública habilitante y no de un consentimiento simultáneo o sucesivo de las partes" ${ }^{72}$ "La fuerza de obligar no procede, en suma, de acuerdo alguno de voluntades entre las partes, sino de la decisión unilateral de la Administración", que se dice, sin embargo, "contratante"73. Por lo tanto, "la única voluntad que crea el contrato es, desde luego, la

66 Boquera Oliver, J. M. La selección de contratistas. Madrid: Instituto de Estudios Políticos, 1963, pp. 153.

67 Monedero Gil, J. I. Doctrina del contrato del Estado. Madrid: Instituto de Estudios Fiscales, 1977.

68 lbíd., p. 255.

69 lbíd., p. 256.

70 Artículo 27,1 de la LCSP. En análogos términos se expresaba el artículo 54 de la ley 13/1995 del 18 de mayo de contratos de las administraciones públicas.

71 Confróntese Martínez López y Muñiz, J. L. "Naturaleza de los contratos públicos a la luz del Derecho español: su fundamento y consecuencias". En Derecho administrativo. Homenaje al profesor M. J. Marienhoff. Buenos Aires: 1998, pp. 947-969.

72 Confróntese J. L. Martínez López y Muñiz. Ibíd., pp. 953.

73 Confróntese J. L. Martínez López y Muñiz. "La adjudicación...”, p. 700. 
de la Administración, aunque justamente al adjudicarlo incorpore la voluntad de la otra parte" ${ }^{\text {"74 }}$.

Desde esta posición doctrinal "no hay diferencias, a esos efectos, entre los actos que adjudican los contratos — públicos - y los constitutivos de meras relaciones estatutarias" (nombramientos de funcionarios públicos, subvenciones, autorizaciones o licencias) ${ }^{75}$. En definitiva, el contrato sería un acto unilateral en su emisión, necesitado de previa aceptación - "sin fuerza jurídica constitutiva" - y contractual en sus efectos.

\section{II.5.2. La explicación que se propone}

No es cuestionable en el Derecho español, ni doctrinal ni legalmente, que exista un contrato (in facto esse) que vincula a las partes. Tampoco lo es que el proceso de formación del contrato (contractus in fieri) esté constituido por actos administrativos unilaterales. Las divergencias surgen en cuanto al papel o funcionalidad del acto de adjudicación. La singularidad de este acto reside en producir los efectos del contrato. La expresión de contrato "encerrado" en un acto administrativo, sin duda brillante, desprende un paradójico halo de metáfora ${ }^{76}$, sobre todo después de poner tanto esfuerzo en negar la autonomía de la voluntad en la administración. Tampoco puede entenderse que el contrato administrativo es prolongación del acto administrativo unilateral ${ }^{77}$.

La adjudicación del contrato es exponente del innegable protagonismo de la administración y denota una iniciativa que inclina a rechazar que el contrato nazca a partir de una aceptación de la oferta del particular por la administración.

El protagonismo de la administración se evidencia en que su función en el contrato es seleccionar una de varias proposiciones, cuando existe una pluralidad, o reconocer que la única existente es conforme con la propuesta anunciada por la administración y determinada por el bloque normativo ${ }^{78}$. Elige, más bien que acepta.

De un modo correlativo se cuestiona el papel de la voluntad del particular en la constitución —o perfección — del contrato. Desde una perspectiva deudora del Derecho privado, la respuesta es definir a los contratos administrativos como contratos de adhesión, lo cual resulta en

74 lbíd., p. 713.

75 Véase Martínez López y Muñiz. “La adjudicación...”; y Casagne y Rivero Ysern (directores). La contratación pública... Para los primeros resulta ilustrativa la teoría del acto condición. (Véase Jèze, G. Los principios generales del Derecho administrativo. C. García Oviedo [traductor]. Madrid: Reus, 1928, pp. 55-58). Para los otros, la teoría del acto necesitado de aceptación, supra.

76 Confróntese J. L. Martínez López y Muñiz, “Los contratos...”, p. 955.

77 Crítica de Ariño ("El enigma...", p. 88) a la tesis de López y Muñiz que, entiendo, no se ajusta al contenido de esta.

78 El artículo 79,1 del TRLCAP y el 129 de la LCSP dicen que "las proposiciones de los interesados deberán ajustarse al pliego de cláusulas administrativas particulares".

UNA CONCEPCIÓN IUSADMINISTRATI-

VISTA DE LOS

CONTRATOS

PÚBLICOS

A CONCEPTION "IUS ADMINISTRATIVISTA" OFTHE PUBLIC PROCUREMENT 
una solución insatisfactoria desde el Derecho público. En este ámbito, la tesis de que la voluntad del particular se reduce a una mera aceptación previa de un acto unilateral que genera un contrato va en contra de una cultura tradicional del Derecho español ${ }^{79}$, y tampoco es la interpretación más sólida del Derecho positivo.

Los actos necesitados de aceptación no se identifican con el contrato. No siempre que la aceptación de una "oferta" definitiva de la administración sea un elemento necesario para la existencia de un acto estamos ante un contrato, aunque se produzca una bilateralidad de la que deriven derechos y obligaciones. Muchos de los supuestos pueden explicarse desde la teoría del acto, en virtud de las cláusulas accesorias, sin tener que acudir al contrato. En esos actos necesitados de aceptación, la vinculación para la administración y para el particular, no es la misma que en los contratos, aunque adopten en ocasiones una veste convencional.

Parece aventurado sostener que los funcionarios de carrera que "en virtud del nombramiento legal, están vinculados a una Administración Pública por una relación estatutaria ${ }^{80}$ " tengan la misma vinculación que deriva de un contrato como lex inter partes. Expresado de conformidad con criterios aceptados comúnmente, en estos casos las obligaciones no son, en rigor, recíprocamente exigibles, "como causa una de la otra"

La voluntad del contratista, en cambio, se une a la resolución de la administración, manifestada en virtud de una concatenación de actos en un procedimiento, de conformidad con lo establecido en el bloque normativo, para constituir un núcleo contractual. No creo que sea necesario acudir a la tesis de un acto unilateral —la adjudicación- que genera un contrato.

La administración y el contratista, de conformidad con sus propios cauces de manifestación, se autovinculan en un acuerdo que sobrepasa la mera yuxtaposición de declaraciones. De esa autovinculación surgen derechos y obligaciones recíprocas. La esencia del acuerdo de voluntades, como se define tradicionalmente el contrato, consiste en esa vinculación mutua que genera.

En el caso de los contratos de la administración, el acto de adjudicación es ejecución del bloque normativo, que implica una autovinculación de aquella en la medida de la proposición elegida del candidato que deviene contratista. La administración con el acto de adjudicación no queda

79 Es, en cambio, propia del Derecho alemán. Véase supra.

80 Artículo 9 de ley 7/2007 del 12 de abril sobre el Estatuto Básico del Empleado Público. Otros empleados públicos adquieren tal condición en virtud de un contrato. Que se trate de laboral no es obstáculo para lo que se expone en el texto; por el contrario, reafirma la tesis manifestada desde el principio en relación con la instrumentalidad de las técnicas jurídicas utilizadas por la administración: en unos casos, el acto -en estos casos, necesitado de aceptación-y, en otros, el contrato.

81 Artículo 1274 del Código Civil. Confróntese Ariño. "El enigma...". 
solo vinculada a la norma, sino también a los términos en que, conforme a ella y a la concreta proposición elegida o seleccionada, se determina el contenido del acto; es, por lo tanto, una doble vinculación que explica la existencia del contrato de una administración pública.

Esa es la funcionalidad del acto de adjudicación prevista por el bloque normativo: una vinculación a lo que constituye auténticamente un contractus lex. Se trata de un acto final de un procedimiento, cuya finalidad es constituir con la voluntad del contratista el núcleo propio de un contrato, entendido more privato como acuerdo de voluntades ${ }^{82}$. Podría decirse que la administración se autovincula, por determinación o previsión de la norma, en el "acuerdo" que supone el duorum in idem placitum consensus.

Una explicación dogmática ${ }^{83}$ puede darse desde la consideración de acto y el contrato como ejecución de la norma. Cuando la voluntad del particular es un elemento del supuesto de hecho previsto en la norma, estamos ante un contrato. En ese caso, la concreción de la norma exige esencialmente la voluntad del particular. En cambio, cuando el supuesto de hecho está totalmente predeterminado en la norma y lo único que falta es su aplicación individual, nos encontramos ante un acto. Esa aplicación es justamente la función del acto. Sucede que, en ocasiones, esa aplicación requiere la aceptación del particular como destinatario de la concreción de la norma. Seguimos estando ante un acto con posibles cláusulas accesorias, pero no ante un negocio jurídico de naturaleza contractual. La voluntad del particular opera como simple condición de eficacia.

En otras palabras, el supuesto de hecho que constituye el contenido del acto está predeterminado; la voluntad del particular queda siempre fuera del contenido de ese acto; la voluntad del particular hace posible que la norma se aplique a un caso singular. En los actos que necesitan de aceptación, la voluntad del particular se yuxtapone al contenido del acto. Por el contrario, la voluntad del particular contribuye a la formación del contenido del contrato. Forma parte del supuesto de hecho en que se va a concretar la norma. Constituye, junto con la "voluntad" de la administración, expresada en el acto de adjudicación, el núcleo mismo, indivisible, del ente jurídico que llamamos "contrato", que deviene ley entre las partes. La voluntad del particular, en este caso, es condición de validez.

82 J. Tornos, en su Comentario..., primera edición, p. 275, hablaba de "dos actos jurídicos que se producen en un mismo momento (acto unilateral de adjudicación y negocio contractual), actos que suponen la finalización del procedimiento administrativo y el nacimiento de la relación contractual". En la segunda edición (pp. 294-295), reconociendo su problematicidad dogmática, habla de un acto que "posee una doble eficacia. Por un lado es el acto final del expediente administrativo y, por otro, es el acto que perfecciona una relación contractual que inicia en este momento su vida jurídica".

83 Confróntese Meilán Gil, J. L. "Para una reconstrucción dogmática de los contratos administrativos". Anuario de la Facultad de Derecho, № 8, 2005, pp. 505-518, Universidad de A Coruña.

UNA CONCEPCIÓN IUSADMINISTRATIVISTA DE LOS CONTRATOS PÚBLICOS

A CONCEPTION "IUS ADMINISTRATIVISTA" OFTHE PUBLIC PROCUREMENT 
El acto de ejecución es, obviamente, un acto administrativo con el que se concluye un procedimiento administrativo. Un acto definitivo, como tal, impugnable. Dentro de la categoría del acto administrativo, tiene una singularidad que le viene de su funcionalidad de perfeccionar un contrato. No es un acto contractual, ni un acto que mute en contrato, que tenga una doble naturaleza o que se limite a producir efectos de contrato.

El acto de adjudicación, como todo acto administrativo, es resultado del ejercicio de una potestad prevista por la ley. Implica, y en ello radica su singularidad, una autolimitación, habilitada por el bloque normativo y determinada por la elección o por la selección de la proposición de un contratista. La declaración en que consiste el acto forma con la manifestación de voluntad del contratista una unidad, un todo en que ambos elementos no se encuentran yuxtapuestos. Esto significa el contractus lex, que vincula administración y contratista. Esa vinculación mutua equivale al acuerdo de voluntades típico del contrato.

La diferencia reside en la diferente naturaleza de quienes dan origen al contrato, cuya actuación está presidida en el caso de la administración por el principio de legalidad y se manifiesta en un acto como ejercicio de una potestad en el ámbito de la competencia reconocida; mientras que, en el caso del contratista, está presidida por la autonomía de la voluntad manifestada en la proposición declarada. El acto de adjudicación ejecuta en un supuesto de hecho concreto, determinado por la proposición elegida, la finalidad de la norma. La administración pública se autovincula con la proposición del contratista finalmente elegido para la consecución del interés general que debe servir.

De la adjudicación depende la validez o la invalidez del contrato ${ }^{84}$ y, por ende, sus efectos, sus derechos y sus obligaciones. Su relevancia jurídica es superior a la formalización del contrato, que ya se ha perfeccionado por la adjudicación ${ }^{85}$.

\section{II.6. La unidad del contrato}

La tesis del acto de adjudicación que genera un contrato se encuentra influida por el rechazo de la doctrina de los actos separados, una importación de origen francés, condicionada por su peculiar sistema contencioso-administrativo, innecesaria e inadecuada en el Derecho español,

84 Confróntese Baca Oneto, V.S. La invalidez de los contratos públicos. Cizur Menor, Navarra: Thomson-Civitas, 2006, en la literatura reciente.

85 La STJCE del 3 de abril de 2008 (asunto C-444/06) resolvió que no es conforme al Derecho comunitario que no se prevea "un plazo de espera obligatorio entre la adjudicación del contrato y su celebración". Resulta discutible la identificación que hace entre formalización —posterior a la adjudicación- y celebración. Esta se encuentra subsumida en la adjudicación. En ese sentido, véase Meilán Gil, J. L., en su prólogo a Pernas García, J. J. Las operaciones in house y el Derecho comunitario de contratos públicos. Madrid: Iustel, 2008. 
en donde desde 1956 quedó eliminada la dualidad de los recursos de anulación y de plena jurisdicción.

La doctrina de los actos separables se abre paso en Francia para salvar los problemas creados por el cambio - revirement- del Conseil d'État al interpretar la legitimación para recurrir los contratos de la administración ${ }^{86}$ reducida solo a las partes en el contrato.

Inicialmente podría interponerse el recurso por "exceso de poder" por quien tuviera interés en el contrato, aunque no fuese, como contratista, parte de él. Aquella interpretación operaba sobre el dogma del tout indivisible, según el cual los actos administrativos que servían de soporte al contrato se hacían uno con él, se incorporaban a él, de modo que la impugnación de aquellos solo podría hacerse impugnando el contrato.

La conjunción de ambas tesis suponía una clara indefensión para quienes, sin haber sido parte en el contrato, tenían interés en que se anulase aquel o al menos alguno de los actos que le habían servido de soporte. Resultaba evidente, además, que el contratista, adjudicatario del contrato, era el menos interesado en su impugnación ${ }^{87}$.

La solución consistió en abandonar la doctrina del "todo indivisible" y separar del contrato los actos que le sirvieron de soporte. Estos recobraron su individualidad como actos administrativos, y podían ser impugnados como tales, aunque en Francia con un resultado "platónico", en expresión del comisario Romieu, ya que la anulación del acto no llevaba consigo la del contrato.

En España, la anulación de uno de esos actos — singularmente el de adjudicación del contrato- acarrea la nulidad del contrato. Desde el punto de vista doctrinal, se ha hecho notar la falta de lógica de ese automatismo, ya que los actos que se separan — independizan - del contrato para hacer posible su impugnación "vuelven después a formar un todo indivisible con él para lograr que su anulación ocasione la nulidad del contrato" 88 .

Desde una perspectiva que podría denominarse "realista" es posible encajar todas las piezas, para lo que las diversas aproximaciones constituyen elementos valiosos. Aún al ser muy importante la vertiente procesal, que ha rendido frutos positivos en la materia, quizá habría que prescindirse de ella en el momento de construir las categorías ${ }^{89}$. Se trata,

86 Confróntese Laubadere, A., F. Moderne y P. Devolvé. Traité des contrats administratives. Tomo 2. Vigésimo quinta edición. París : L.G.D.J, 1984, pp. 1035 y siguientes.

87 Confróntense Boquera "La selección...", p. 182 y siguientes; Solas. Contratos..., pp. 231 y siguientes; Macera. "La teoría...", p. 62 y siguientes, todos con amplia exposición de la doctrina y la jurisprudencia.

88 Boquera, "La selección...", p. 209

89 Confróntese Meilán. "El proceso de la definición del Derecho administrativo". Administración pública en perspectiva. Madrid: ENAP (1967) y Universidad de A Coruña (1996), pp. 39-41.

UNA CONCEPCIÓN IUSADMINISTRATIVISTA DE LOS CONTRATOS PÚBLICOS

A CONCEPTION "IUS ADMINISTRATIVISTA" OFTHE PUBLIC PROCUREMENT 
en primer término, de afirmar la unidad del contrato en sus fases de preparación, perfección, ejecución y extinción.

$\mathrm{Ni}$ los actos se subsumen en el contrato, ni este se encierra en el acto de adjudicación. Los actos conservan su individualidad y su función en el contrato como una unidad. Por eso puede existir una comunicabilidad de la invalidez de un acto preparatorio o del de ejecución al contrato. Constituyen una parte esencial de aquel, como expresión de la voluntad de la administración que, con la del contratista, crea un núcleo de derechos y obligaciones.

No es preciso "desintegrar" el contrato y construir la ficción jurídica de unos actos separables de él por plausibles razones de justicia, a cuyo servicio se pone la legitimación procesal. Lo que procede es examinar su función en el contrato. En unos casos se insertan en el procedimiento de preparación, que culmina en la adjudicación y sigue en la formalización. Otros pueden aparecer en la fase de ejecución o en la extinción del contrato, cuando se trata de contratos administrativos. El ejercicio de las prerrogativas de la administración se realiza por actos cuando el contrato ya se ha perfeccionado.

Los actos serán impugnables de acuerdo con su naturaleza y su función en el contrato: por ejemplo, para los actos preparatorios, como actos de trámite que son, se tomará en cuenta su incidencia en el acto definitivo de la adjudicación. Su eventual declaración de nulidad lleva consigo la del mismo contrato y, además, dará lugar a la indemnización de los daños y perjuicios ${ }^{90}$, para lo que podrán tenerse en cuenta actuaciones que se hubiesen realizado.

\subsection{Las prerrogativas de la administración}

En los contratos administrativos se reconocen prerrogativas de la administración pública: interpretarlos, resolver las dudas que ofrezca su cumplimiento, modificarlos por razones de interés público, acordar su resolución y determinar los efectos de esta, dentro de los límites y con sujeción a los requisitos y efectos señalados en la ley ${ }^{91}$. Esta predeterminación legal es clave. No se trata de la imposición unilateral de la administración o de una previsión surgida en el iter del contrato. El contratista conoce de antemano lo que está determinado en la ley y que es de obligado cumplimiento para la administración que contrata: "Los contratos deberán cumplirse a tenor de sus cláusulas sin perjuicio de las prerrogativas establecidas por la legislación a favor de la Administración Pública" $"$. 
Esa previsión de la ley supera los inconvenientes de la interpretación exclusivamente jurisprudencial que ha revelado una extraordinaria finura jurídica para atender a los intereses generales y reconocer los derechos del particular contratista; así superan el auténtico "callejón sin salida" de la interpretación civilista ${ }^{93}$.

Más que de prerrogativas, debería hablarse de potestades de la administración justificables por el fin atribuido que es el canon para medir su ejercicio en relación con la adecuación al Derecho y por el que es susceptible de control jurisdiccional. Como se ha dicho lapidariamente en sede judicial, "las potestades que la Constitución y las leyes encomiendan a la Administración no son privilegios, sino instrumentos normales para el cumplimiento de sus fines y, en definitiva, para la satisfacción de los intereses generales"94.

Desde la perspectiva constitucional del interés general o público resulta discutible que sea necesaria la prerrogativa de la interpretación y resolución de dudas. Habría que entroncarlas en un auténtico privilegio enlazado con el de la autotutela de la administración, una construcción doctrinal discutible ${ }^{95}$.

La modificación se corresponde a lo que tradicionalmente se conoce como potestas o ius variandi. En el supuesto contractual, esa vinculación se concreta en el fin especial del correspondiente contrato, ya que de otra manera se desnaturalizaría: no se estaría ante una modificación del contrato, sino ante un nuevo contrato con vulneración de los principios de publicidad y concurrencia ${ }^{96}$.

La administración no puede renunciar a la potestad ${ }^{97}$, que se correlaciona necesariamente con "la inmutabilidad del fin o la inmutabilidad del servicio" 98 , hasta el punto de que puede hablarse de una obligatoriedad de su ejercicio ${ }^{99}$, impulsada, en ocasiones, por la presión social del progreso técnico ${ }^{100}$. Desde esa perspectiva se ha calificado como una "facultad reglada" ${ }^{101}$, aunque con propiedad habrá que sostener que se trata de una potestad discrecional que contiene, como todas las de su naturaleza, elementos reglados ${ }^{102}$.

93 Confróntese Laubadere. Traité..., pp. 709 y siguientes. Monográficamente en Meilán Gil, J. L. La cláusula de progreso de los servicios públicos. Madrid: I.E.A., 1968; sobre las respuestas del Derecho español, francés e italiano al conflicto del gas y la electricidad en el siglo XIX.

94 STS del 27 de marzo de 1986.

95 Confróntese Meilán Gil. "Sobre el acto administrativo y los privilegios de la administración". Administración pública en perspectiva. Universidade da Coruña, 1996, pp. 391 y siguientes.

96 Confróntese Ariño, Teoría..., pp. 229-230, con cita de doctrina francesa sobre el changement de nature.

97 Ibíd., p. 225.

98 STS del 11 de octubre de 1979 (RJ 1979/3448).

99 Confróntese Villar Excurra y Martí Badaroux en los Comentarios... de Ariño, p. 800.

100 Confróntese Meilán. Progreso tecnológico y servicios públicos. Thomson-Civitas, 2006.

101 Confróntese STS del 11 de abril de 1984 (RJ. 1984/1920)

$102 \mathrm{El}$ residuo de desigualdad posicional dentro del contrato evidenciado por la potestad -mejor que prerrogativa y más todavía que privilegio- que reconoce la ley en los contratos administrativos se

UNA CONCEPCIÓN IUSADMINISTRATI-

VISTA DE LOS

CONTRATOS

PÚBLICOS

A CONCEPTION "IUS ADMINISTRATIVISTA" OFTHE PUBLIC PROCUREMENT 
El sometimiento al principio de legalidad y al contrato, como lex inter partes, justifica que el órgano de contratación solo podrá introducir modificaciones en aquel por razones de interés público, con justificación en el expediente. La finalidad de la modificación es "atender a causas imprevistas". Las "nuevas necesidades" se formulaban anteriormente como una disyuntiva a la imprevisión. Tendrían que subsumirse en las "causas imprevistas" con la dificultad adicional de que ahora no se considera como modificación la ampliación del objeto del contrato, "dirigida a satisfacer finalidades nuevas no contempladas en la documentación preparatoria del mismo [sic]".

Por ello la LCSP niega la consideración de modificaciones del contrato a las "ampliaciones de su objeto que no puedan integrarse en el proyecto inicial mediante una corrección del mismo o que consistan en la realización de una prestación susceptible de utilización o aprovechamiento independiente". Esas ampliaciones han de ser contratadas de forma separada; podrán ser consideradas como prestaciones complementarias, no previstas inicialmente y que, por una circunstancia imprevista, pasan a ser necesarias para ejecutar la obra.

En definitiva, la potestad viene limitada por las previsiones de la ley para evitar que se desnaturalice la prerrogativa con el abuso de reformas, advertida por el consejo de Estado ${ }^{103}$ y por la jurisprudencia ${ }^{104}$. Se ha ido acotando cada vez más la discrecionalidad de la administración que, como toda potestad de esa naturaleza, difiere del libre arbitrio y es jurisdiccionalmente controlable.

Se ha dicho (Rivero) que la exorbitancia puede entenderse como una "derogación en menos". En realidad, viene a subrayarse el diferente comportamiento de la administración y del particular, de acuerdo con el régimen jurídico que afecta a los contratos, como pone de manifiesto el procedimiento que tiene que seguir aquella para la celebración del contrato. Se manifiesta esa diferencia, por ejemplo, en cuanto a la prórroga de los contratos administrativos, cuyo régimen ha ido reduciendo progresivamente la libertad de la administración.

Las prórrogas de la duración han de estar previstas en el contrato; sus características han de permanecer inalterables durante el período de aquellas y — esto es sintomático en garantía del principio de igualdadla concurrencia para que la adjudicación del contrato haya sido realizada

contrapesa por el juego del equivalente económico. En ello consiste, en palabras de Ariño, una de las peculiaridades del contrato administrativo: "la reconstrucción de la igualdad contractual por la vía económica". En El enigma... p. 16.

103 En el dictamen 1629/91 de 23-I-92 se dice que "gran parte de las modificaciones contractuales son referibles a motivaciones que desnaturalizan la institución".

104 STS del 22 de junio de 1982 (artículo 2323). En la STSJ Madrid del 9 de marzo de 2001 (RJ 2001/909) se dice que esa potestad "concebida en salvaguarda del interés general, ha devenido frecuentemente, por causa de un empleo indebido, en conveniencia para el contratista". 
teniendo en cuenta la duración máxima de aquel, incluidos los períodos de prórroga. Y, por si fuera poco, la prórroga no puede producirse por el consentimiento tácito de las partes.

\section{III.REFLEXIÓN CONCLUSIVA}

La construcción jurídica de los contratos de la administración debe realizarse desde la perspectiva constitucional que asigna a aquella la misión de servir a los intereses generales, con sometimiento pleno a la ley y al Derecho, y con eficacia. Para su cumplimiento, y buscando la colaboración de los particulares, la administración puede acudir al acto unilateral o al contrato.

Para la configuración de los contratos no es necesario partir de los regulados por el Derecho civil. Ambas categorías jurídicas participan del superconcepto "contrato" al que remite la unidad última del Derecho.

La naturaleza de la administración explica que su resolución, que formará con la voluntad del contratista el núcleo esencial de un contrato con vinculación mutua, se adopte mediante un procedimiento compuesto de actos. Esto es característico de los contratos de las administraciones públicas, una diferencia inequívoca respecto de la contratación entre particulares.

La administración es titular de potestades que han de ser consideradas en función del interés al que se aplican y, desde ese fin, jurisdiccionalmente justificadas y controlables. Previstas en la ley, no son privilegios impropios de un Estado social y democrático de Derecho, en el que los derechos fundamentales de la persona ocupan un lugar central y vinculan a todos los poderes públicos. 